\title{
Applying Multivariate and Univariate Analysis of Variance on Socioeconomic, Health, and Security Variables in Jordan
}

\author{
Faisal G. Khamis ${ }^{1,2, *}$, Ghaleb A. El-Refae ${ }^{3}$ \\ ${ }^{1}$ University of Guelph-Humber, Toronto, ON, Canada \\ ${ }^{2}$ Faculty of Liberal Arts \& Sciences and Innovative Learning, Humber College, Toronto, ON, Canada \\ ${ }^{3}$ Al-Ain University of Science and Technology, Al Ain, UAE
}

\begin{abstract}
Many researchers have studied socioeconomic, health, and security variables in developed countries; however, very few studies used multivariate analysis in developing countries. The current study contributes to the scarce literature about the determinants of the variance in socioeconomic, health, and security factors. Questions raised were whether the independent variables (IVs) of governorate and year impact the socioeconomic, health, and security dependent variables (DVs) in Jordan? Whether the marginal mean of each DV in each governorate and each year is significant? Which governorates are similar in the difference between means of each DV? Whether these DVs vary? The main objectives were to determine the source of variances in DVs, collectively and separately, testing which governorates are similar and which diverge for each DV.
\end{abstract}

The research design was a time-series and cross-sectional analysis. The main hypotheses are that IVs affect DVs collectively and separately. Multivariate and univariate analyses of variance were carried out to test these hypotheses. The population of 12 governorates in Jordan and the available data of 15 years (2000-2015) accrued from several Jordanian statistical yearbooks. We investigated the effect of two factors of governorate and year on the four DVs of divorce, mortality, unemployment, and crime. Also, descriptive statistics were calculated for each DV in each governorate and each year. However, we performed a visual and numerical inspection of how each DV changed over time in each governorate compared with DV change in other governorates. The rate of divorce, mortality, and crime, and the percentage of unemployment were used in the analyses. All DVs were transformed into a multivariate normal distribution.

Based on the multivariate analysis of variance, we found a significant effect in IVs on DVs with $p<0.001$. Based on the univariate analysis, we found a significant effect of IVs on each DV with $p<0.001$. Except for the effect of the year factor on unemployment was not significant with $p=0.642$. Besides, the grand and marginal means of each DV in each governorate and each year were significant based on a 95\% confidence interval. Furthermore, most governorates are not similar in DVs with $p<0.001$. We concluded that the two factors produce significant effects on DVs, collectively and separately. Based on these findings, the government can distribute its financial and physical resources to governorates more efficiently. By identifying the sources of variance that contribute to the variation in DVs, insights can help inform focused variation prevention efforts.

Keywords MANOVA, mortality, divorce, unemployment, crime, governorate, year, Jordan, ANOVA, hypothesis test, and means

\section{AMS 2010 subject classifications 62F03}

DOI: $10.19139 /$ soic-2310-5070-506

\footnotetext{
*Correspondence to: Faisal G. Khamis (Email: faisal_alshamari@yahoo.com). University of Guelph-Humber and Humber College, 205 Humber College Blvd., Toronto, ON, Canada.
}

ISSN 2310-5070 (online) ISSN 2311-004X (print)

Copyright (C) 2020 International Academic Press 


\section{Introduction}

We investigated several socioeconomic, health, and insecurity issues across the governorates in Jordan over time. We can represent these issues by the variance in the dependent variables (DVs) of divorce, mortality, unemployment, and crime, between governorates and between years. Studying sources of variance in these DVs is important sociologically, economically, and medically, and to maintain safety. The increasing levels and persistence of high levels in these DVs over time could result in many serious problems in society. These problems are one of the biggest challenges any country can face, so nations must monitor their negative consequences over time and across space. The existence of variance in DVs can negatively affect population health and productivity and this variance may increase over time. Low increases in DVs could consume the government's limited financial, physical, and human-capital resources. The persistence of variance in at least one of these DVs and the increase in its level could negatively affect national development in all fields.

It is necessary to solve divorce as a social problem, mortality as a health problem, unemployment as an economic problem, and crime as an insecurity problem. In addition, these problems correlate directly and indirectly; hence, the appearance of at least one of them may affect the appearance of others. Family breakdown can have catastrophic social effects. An increase in mortality, especially in working-age adults and in unemployment rates are more likely to affect economic growth. Unemployment may create feelings of rejection and hatred in unemployed people about their society, separating them from socioeconomic interactions with society. In addition, unemployed people may not believe in or wish to obey society's regulations and rules, which could lead to criminal behaviors. Those under stress may expose to multiple mental illnesses, which, in turn, can lead to divorce or death. The loss of one couple's income could lead to extreme poverty for the household, increase relational stress in the family, and raise the possibility of divorce. Unemployment and crime can lead to a lack of control for all family members in providing living requirements and social support for children. Therefore, the present study aims to suggest a solution to reduce the variance in these correlated problems in Jordan, which could improve the quality of life and increase life satisfaction.

Many studies investigated the current research variables in many developing and developed countries but we found limited studies in Jordan. The present study relates to previous studies in studying some socioeconomic, health, and security variables and in using different analysis units of place, such as city and state. Researchers in previous studies used different statistical techniques in their analysis and did not examine all DVs examined in the current study; thus, this study fills gaps in the literature. Furthermore, this study has limited similarity with previous studies in its objectives. Hence, we investigated several primary and secondary hypotheses.

The primary hypotheses were no main governorate effect exists, collectively and separately, on DVs; and no main year effect exists, collectively and separately, on DVs. Secondary hypotheses follow: The grand and marginal means of each DV equals zero. The mean difference between two governorates in each DV equals zero. Therefore, study objectives were to determine the source of variance in DVs, collectively and separately. We investigated which independent variable (IV) - the governorate or the year-affects DVs, collectively and separately, more than another; which governorates are similar and which differ in DVs; how much variance in each DV can be accounted for by each IV; and the significance of grand and marginal means of each DV in each governorate and each year. We provided visual and numerical inspection of how each DV changed over time in each governorate compared with DV change in other governorates. The main goal was to seek sources of variance in DVs between governorates and between years; thus, the research design was cross sectional using time-series data. We analyzed the data simultaneously to discern if the variance in DVs between governorates and between years was significant or not. That is, we used cross-sectional data to investigate the variance between governorates and time-series data to examine the variance between years.

Although the literature had few articles closely related to the current study topic, we reviewed some previous studies that relate to the topic. In Jordan, multiple local spatial relationships between mortality, unemployment, divorce, and crime were significant in several western governorates using Lee's global and local spatial measures [11]. In Utrecht, Netherlands, using a longitudinal panel study, De Goede and Spruijt [4] found that parental divorce negatively affects adolescent health and being unemployed or having been unemployed negatively impact psychological health. Job loss and broken partnerships increased the risk of premature mortality in Denmark 
[12]. Unemployment often has a strong negative effect on people's life satisfaction, analyzed using reliability, validity, and sensitivity measures [5]. This negative effect may lead to several social and insecurity problems such as divorce and crime. Data covering 35 years (1950-1985) for 12 nation revealed unemployment aligns with lower marriage and birth rates and higher divorce rates [13]. Lester and Yang [14] concluded that unemployment related to suicide rates in the United States but not in Australia, using identical data sets from 1946 to 1984. In Japan, those experiencing marital violence and those who were not employed were less likely to use healthcare when they experienced marital violence, analyzed using multiple logistic regression analysis [17]. In Hong Kong, a spatial-regression approach showed that high-risk areas, located in an urban high-density environment with higher socioeconomic deprivation, had increased mortality [18]. Kantar and Aktas [9] found a significant neighboring effect in unemployment rates at the provincial level in Turkey over time, analyzed using global and local spatial autocorrelation statistics and mapping analysis.

We applied a multivariate and univariate analysis of variance (ANOVA) technique to the data. The multivariate ANOVA seeks causal impact of a nominal-level IV (factor) on multiple DVs. In the current study, we examined the effect of two factors of governorate and year on the four socioeconomic, health, and security DVs of divorce, unemployment, mortality, and crime. The governorate factor represents the place level (12 levels or governorates) and the year factor represents the time level (16 years). Researchers use ANOVAs to assess group differences on a metric DV. Multivariate analysis of variance (MANOVA) is useful when researchers control at least one IV to determine the effect on multiple DVs simultaneously. ANOVA and MANOVA provided the tools necessary to judge if an observed difference between groups was due to the IV effect or random variability.

Theoretically, several assumptions are required before applying the MANOVA technique; we tested these assumptions in some detail, explained in the analysis subsection. However, in most previous studies, researchers ignored these assumptions, did not explain them well, or investigated without finding proper solutions when assumptions violated. Furthermore, violating these assumptions could affect study results, which may affect the quality of conclusions. In addition, violations in these assumptions consider a statistical-methodology problem. Another theoretical implication was explaining the variance-covariance matrix notations of the random-error component in some detail, which were not provided in non-statistical articles and were quite limited in the statistical literature.

From a practical viewpoint, studying several IVs and DVs, compared with previous studies, expects to guide further research on how to analyze this number of variables and other related variables in the current study to provide an accurate assessment. In addition, researchers usually apply ANOVA and MANOVA techniques in the fields of agriculture, physics, pharmacy, and chemistry; however, in the current study, we applied them in the fields of socioeconomics, health, and security. To our best knowledge and based on the literature review, this is the first empirical study examining IVs and DVs together using MANOVA and ANOVA techniques over a relatively long time period across all Jordanian governorates.

The current study includes five main sections. The introduction includes the problem statement and its importance, the hypotheses and their correspondence to the research design, and the relevant related literature. The materials and methods section describes the variables used in the study in some detail and explains the research methodology. Detailed results are reported using tables and figures in the results section. Evaluation and interpretation of results and their implications appear in the discussion section. The study concludes with recommendations.

\section{Materials and Methods}

\subsection{Data}

We used two independent or grouping variables (IVs): The governorate variable with 12 groups (governorates) and the year variable with 16 groups (2000 to 2015). We studied the effect of these IVs on four DVs: divorce, crime, mortality, and unemployment. We used the divorce rate (DR), the crime rate (CR), the mortality rate (MR), and the unemployment percentage (UP) in the analysis. The UP in the $i$ th governorate is the number of unemployed persons in the $i$ th governorate divided by the number of unemployed people in the country times 100 . The rate of 
the DV in the $i$ th governorate can be calculated as

$$
\text { rate }_{i}=\left(\frac{O_{i}}{n_{i}}\right) 1000, \quad i=1,2, \ldots, 12,
$$

where, $O_{i}=$ Observed number of such DV, and $n_{i}=$ Population size in the $i$ th governorate.

\subsection{Analysis}

We applied MANOVA approach for several reasons. A series of $F$-tests with ANOVA results in several analytical problems [7]. (a) ANOVA could result in an inflated Type-I error rate. (b) ANOVA ignores the possibility that some composite of DVs might provide reliable evidence of overall group differences. (c) ANOVA does not consider intercorrelations between DVs (between- and within-levels of each factor). (d) Single DVs seldom completely capture the phenomenon under study. MANOVA solves the first problem by providing a single overall-fit test of group differences at a specified $\alpha$ level. MANOVA solves the second problem by implicitly forming and testing the linear combination of DVs, providing the strongest evidence of overall group differences, which suggests that the variables are more meaningful taken together than considered separately. However, several statistical techniques can be used in analyzing the time series and cross-sectional data used in the current study such as spatial and temporal statistics and regression-analysis models. Based on the study objectives, investigating the variation in DVs between governorates and between years, we used the MANOVA technique.

In this study, we used a between-subjects and within-subject design. The assumptions in using the MANOVA to be tested follow: (a) the distribution of DVs is multivariate normal within groups [7]. This assumption was checked by examining the estimated residuals. We used Henze-Zirkler's multivariate normality test such that $\mathrm{HZ}=2.95$ with $p<.001$. Test results showed a violation of this assumption. Thus, we transformed the DVs to multivariate normal distribution using the Box-Cox transformation. Table 1 shows results of Shapiro-Wilk normality test for transformed data. (b) The variance-covariance matrices of DVs are homogeneous. Box's M test was used to test the equality of covariance matrices between the 12 governorates. Box $F(110,29312.1)=1.22$ with $p<.055$ indicates we do not reject the null hypothesis that the covariance matrices are equal using $\alpha=.05$. (c) To test the MANOVA assumption that the DVs are significantly, but is not too correlated, we used Bartlett's test of sphericity. We found the approximate $\chi_{i(d f=9)}^{2}=56.21$ with $p=.001$ significant. This statistic tests the null hypothesis that the residual covariance matrix is proportional to an identity matrix where we rejected the null hypothesis based on the $p$-value. This process satisfied the necessary level of intercorrelation to justify the use of MANOVA.

2.2.1. Multivariate analysis of variance We used a MANOVA to test the hypothesis that one or more IVs, or factors, affect a set of two or more DVs. Researchers use MANOVA in two major situations. The first is when

Table 1. Results of Shapiro-Wilk normality test for transformed data using $\alpha=.01$

\begin{tabular}{lllllllll}
\hline & \multicolumn{8}{c}{ Statistic $(p$-value $)$} \\
\cline { 2 - 8 } Governorate & \multicolumn{1}{c}{ Divorce } & \multicolumn{2}{c}{ Crime } & \multicolumn{3}{c}{ Mortality } & \multicolumn{1}{c}{ Unemployment } \\
\hline Ajlun & 0.90 & $(.093)$ & 0.94 & $(.371)$ & 0.90 & $(.075)$ & 0.92 & $(.185)$ \\
Amman & 0.88 & $(.041)$ & 0.94 & $(.371)$ & 0.87 & $(.025)$ & 0.96 & $(.604)$ \\
Aqaba & 0.89 & $(.056)$ & 0.88 & $(.034)$ & 0.93 & $(.254)$ & 0.93 & $(.257)$ \\
Balqa & 0.94 & $(.375)$ & 0.93 & $(.282)$ & 0.88 & $(.039)$ & 0.96 & $(.636)$ \\
Irbid & 0.92 & $(.195)$ & 0.91 & $(.129)$ & 0.82 & $(.005)$ & 0.94 & $(.314)$ \\
Jarash & 0.92 & $(.183)$ & 0.93 & $(.216)$ & 0.82 & $(.005)$ & 0.97 & $(.888)$ \\
Karak & 0.89 & $(.059)$ & 0.89 & $(.062)$ & 0.94 & $(.368)$ & 0.97 & $(.886)$ \\
Ma'an & 0.88 & $(.037)$ & 0.88 & $(.039)$ & 0.91 & $(.113)$ & 0.90 & $(.076)$ \\
Madaba & 0.85 & $(.013)$ & 0.91 & $(.111)$ & 0.96 & $(.733)$ & 0.90 & $(.075)$ \\
Mafraq & 0.97 & $(.852)$ & 0.95 & $(.522)$ & 0.96 & $(.626)$ & 0.96 & $(.691)$ \\
Tafiela & 0.95 & $(.441)$ & 0.91 & $(.097)$ & 0.95 & $(.511)$ & 0.95 & $(.431)$ \\
Zarqa & 0.95 & $(.532)$ & 0.92 & $(.180)$ & 0.93 & $(.206)$ & 0.97 & $(.900)$ \\
\hline
\end{tabular}


multiple DVs correlate and the researcher desires a single, overall statistical test on this set of variables rather than performing multiple individual tests. The second is to explore how IVs influence some patterning of response on DVs. Therefore, we investigated the effect of the governorate and year factors on four DVs: DR, CR, MR, and UP. We assumed that governorates and years do not interact. That is, the difference in DVs between the governorates is the same in all years. We represent the two-way MANOVA model in a matrix form as

$$
\boldsymbol{y}_{i j k}=\boldsymbol{\mu}+\boldsymbol{\tau}_{i}+\boldsymbol{\beta}_{j}+\boldsymbol{\varepsilon}_{i j k} \quad\left\{\begin{array}{l}
i=1,2, \ldots, 12 \text { governorates } \\
j=1,2, \ldots, 16 \text { years } \\
k=1,2, \ldots, 12 \times 16=192,
\end{array}\right.
$$

where $\boldsymbol{y}_{i j k}$ is a $4 \times 1$ observation vector of four DVs measured at the $i$ th governorate in the $j$ th year, $\boldsymbol{\mu}$ is a $4 \times 1$ vector of overall means of four DVs, $\boldsymbol{\tau}_{i}$ is a $4 \times 1$ vector of the $i$ th governorate effect, $\boldsymbol{\beta}_{j}$ is a $4 \times 1$ vector of the $j$ th year effect, and $\varepsilon_{i j k}$ is a $4 \times 1$ vector of the random-error component, which we assumed was normally and independently distributed with $\boldsymbol{\mu}=\mathbf{0}$ and variance-covariance matrix, $\Sigma$ :

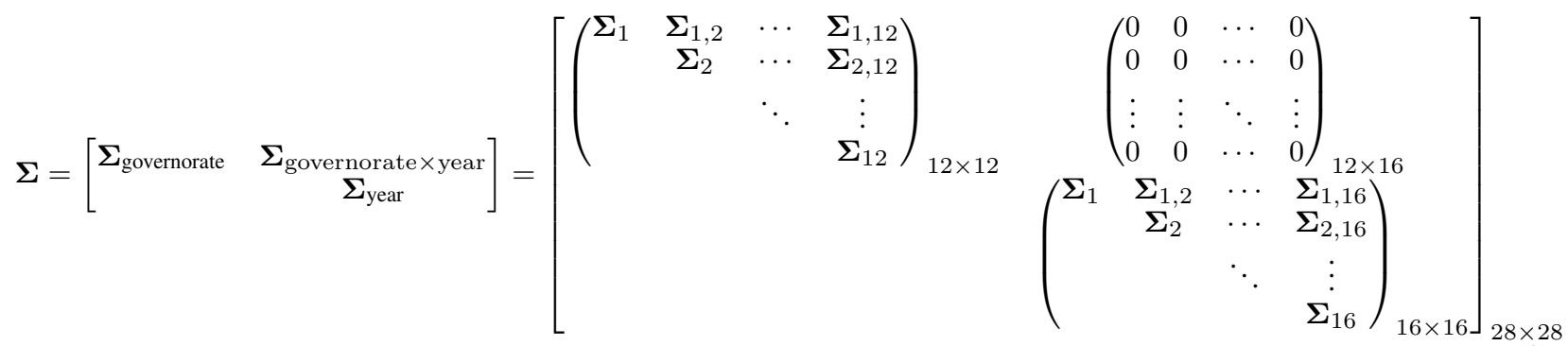

where, each $\boldsymbol{\Sigma}$ is a $4 \times 4$ matrix. The sigma notations in the $\boldsymbol{\Sigma}_{\text {governorate }}$ can be explained as follows: $\boldsymbol{\Sigma}_{1}, \boldsymbol{\Sigma}_{2}$, $\ldots, \Sigma_{12}$ on the diagonal are the variance-covariance matrices of 12 governorates and sigma notations outside the diagonal are the variance-covariance matrices between the $i$ th and $j$ th governorates. The $\boldsymbol{\Sigma}_{1}$ and $\boldsymbol{\Sigma}_{1,2}$, for example, can be represented as

$$
\boldsymbol{\Sigma}_{1}=\left[\begin{array}{cccc}
\sigma_{1}^{2} & \sigma_{12}^{2} & \sigma_{13}^{2} & \sigma_{14}^{2} \\
& \sigma_{2}^{2} & \sigma_{23}^{2} & \sigma_{24}^{2} \\
& & \sigma_{3}^{2} & \sigma_{34}^{2} \\
& & & \sigma_{4}^{2}
\end{array}\right]_{4 \times 4}
$$

where, $\sigma_{1}^{2}, \sigma_{2}^{2}, \sigma_{3}^{2}$, and $\sigma_{4}^{2}$ are the variances of the divorce, crime, mortality, and unemployment, respectively, in Governorate $1, \sigma_{12}^{2}$ is the covariance between divorce and crime in Governorate 1.

$$
\boldsymbol{\Sigma}_{1,2}=\left[\begin{array}{cccc}
\sigma_{11}^{2} & \sigma_{12}^{2} & \sigma_{13}^{2} & \sigma_{14}^{2} \\
& \sigma_{22}^{2} & \sigma_{23}^{2} & \sigma_{24}^{2} \\
& & \sigma_{33}^{2} & \sigma_{34}^{2} \\
& & & \sigma_{44}^{2}
\end{array}\right]_{4 \times 4}
$$

where, $\sigma_{11}, \sigma_{22}, \sigma_{33}$, and $\sigma_{44}$ are the variances of divorce, crime, mortality, and unemployment, respectively, collectively in Governorates 1 and 2, $\sigma_{12}$ is the covariance between divorce in Governorate 1 and crime in Governorate 2, and other variances and covariances can be found by the reader. The sigma notations in the $\boldsymbol{\Sigma}_{\text {year }}$ can be obtained accordingly, that is, instead of applying the governorate factor, the year factor can be applied.

In matrix form, we tested the following hypotheses collectively for all DVs:

$$
\begin{gathered}
H_{0}: \boldsymbol{\tau}_{1}=\boldsymbol{\tau}_{2}=\cdots=\boldsymbol{\tau}_{12}=0 \quad \text { (no main governorate effect) } \\
\left.H_{1}: \boldsymbol{\tau}_{i} \neq 0 \quad \text { (for at least one } i\right)
\end{gathered}
$$

and

$$
\begin{aligned}
H_{0}: \boldsymbol{\beta}_{1}= & \boldsymbol{\beta}_{2}=\cdots=\boldsymbol{\beta}_{16}=0 \quad \text { (no main year effect) } \\
& H_{1}: \boldsymbol{\beta}_{j} \neq 0 \quad \text { (for at least one } j \text { ) }
\end{aligned}
$$


Table 2. Experimental Design

\begin{tabular}{ccccccccc}
\hline & \multicolumn{7}{c}{ Year } & Marginal \\
\cline { 2 - 7 } Governorate & 1 & 2 & $\ldots$ & $j$ & $\ldots$ & 16 & mean \\
\hline 1 & $y_{11}$ & $y_{12}$ & $\ldots$ & $y_{1 j}$ & $\ldots$ & $y_{116}$ & $\mu_{1}$ \\
2 & $y_{21}$ & $y_{22}$ & $\ldots$ & $y_{2 j}$ & $\ldots$ & $y_{216}$ & $\mu_{2}$ \\
$\vdots$ & $\vdots$ & $\vdots$ & $\ddots$ & $\vdots$ & $\ldots$ & $\vdots$ & $\vdots$ \\
$i$ & $y_{i 1}$ & $y_{i 2}$ & $\ldots$ & $y_{i j}$ & $\ldots$ & $y_{i 16}$ & $\mu_{i}$. \\
$\vdots$ & $\vdots$ & $\vdots$ & $\vdots$ & $\vdots$ & $\ddots$ & $\vdots$ & $\vdots$ \\
12 & $y_{121}$ & $y_{122}$ & $\ldots$ & $y_{12 j}$ & $\ldots$ & $y_{1216}$ & $\mu_{12}$. \\
Marginal mean & $\mu \cdot 1$ & $\mu \cdot 2$ & $\ldots$ & $\mu \cdot j$ & $\ldots$ & $\mu \cdot 16$ & $\mu$. \\
\hline
\end{tabular}

where, $\boldsymbol{\tau}$ and $\boldsymbol{\beta}$ are an $4 \times 1$ effect vectors of four DVs.

Testing the null hypotheses that the governorate effects, $\boldsymbol{\tau}_{i}$, and the year effects, $\boldsymbol{\beta}_{j}$, are equal to zero is equivalent to testing the null hypothesis that vectors of means on four DVs across governorates and over years are equal. Table 2 shows the experimental design with the two factors of governorate and year: $\boldsymbol{y}_{i j}$ represents a $4 \times 1$ vector of four DVs measured in the $i$ th governorate and $j$ th year, and their corresponding marginal means.

2.2.2. Univariate analysis of variance Even if we obtained a significant value of the $F$-statistic and the overall difference of means was significant, the $F$-statistic does not tell us how the mean scores vary between the levels of each factor of the governorate and year. We used post-hoc tests as a follow-up analysis to discover which specific DVs were affected by which factors. In addition, we investigated which pairs of combinations $\left(C_{2}^{12}\right.$ or 66 pairs $)$ of two governorates for each DV were significantly different. Therefore, we applied the two-way ANOVA approach. The observation, $y_{i j}$, of such a DV, measured at the $i$ th governorate in the $j$ th year, assuming governorates and years do not interact, may be represented by the two-way ANOVA model:

$$
y_{i j}=\mu+\tau_{i}+\beta_{j}+\varepsilon_{i j k}\left\{\begin{array}{l}
i=1,2, \ldots, 12 \text { governorates } \\
j=1,2, \ldots, 16 \text { years } \\
k=1,2, \ldots, 12 \times 16=192
\end{array}\right.
$$

where, $\mu$ is the overall mean, $\tau_{i}$ is the $i$ th governorate effect, $\beta_{j}$ is the $j$ th year effect, and $\varepsilon_{i j k}$ is a random-error component assumed to be normally and independently distributed with mean zero and variance $\sigma^{2}$.

Therefore, we tested the following hypotheses, using $\alpha=.05$ as a level of significance, for each DV:

$$
\begin{gathered}
H_{0}: \tau_{1}=\tau_{2}=\cdots=\tau_{12}=0 \quad \text { (no main governorate effect) } \\
H_{1}: \tau_{i} \neq 0 \quad \text { (for at least one } i \text { ) }
\end{gathered}
$$

and

$$
\begin{gathered}
H_{0}: \beta_{1}=\beta_{2}=\cdots=\beta_{16}=0 \quad \text { (no main year effect) } \\
H_{1}: \beta_{j} \neq 0 \quad \text { (for at least one } j \text { ) }
\end{gathered}
$$

Furthermore, based on the estimated marginal means, we tested the null hypothesis stating that $(\mu=0)$ for each DV in each governorate and each year. In addition, we tested the null hypothesis stating that the mean difference between the $i$ th and $j$ th governorate equals zero for each DV $\left(\mu_{i}-\mu_{j}=0\right)$. 


\section{Results}

Tables 3 and 4 show descriptive statistics for each DV at each governorate and in each year respectively before transforming the data to the multivariate normal distribution. We found the highest and lowest means in the DR in Amman and Ma'an, respectively. We found the highest and lowest means in the CR in Madaba and Jarash, respectively. We found the highest and lowest means in the MR in Madaba and Mafraq, respectively. We found the highest and lowest means in the UP in Madaba and Ma'an, respectively.

From data shown in Table 4, overall, we found the change in the mean of MR was slightly stable over the period 2000-2015. We found the highest and lowest means in the MR in 2007 and 2015, respectively. We found the

Table 3. Descriptive Statistics for Each Dependent Variable in Each Governorate, 2000-2015

\begin{tabular}{|c|c|c|c|c|c|c|c|c|c|c|c|c|}
\hline \multirow[b]{2}{*}{ Governorate } & \multicolumn{4}{|c|}{ Mean } & \multicolumn{4}{|c|}{ Standard Deviation } & \multicolumn{4}{|c|}{ Coefficient of Variation } \\
\hline & DR & $\mathrm{CR}$ & MR & UP & DR & CR & MR & UP & DR & $\mathrm{CR}$ & MR & UP \\
\hline Irbid & 1.99 & 5.11 & 3.25 & 19.73 & 0.44 & 2.16 & 0.27 & 2.13 & 22.28 & 42.30 & 8.35 & 10.78 \\
\hline Ajlun & 1.34 & 4.05 & 2.36 & 2.58 & 0.43 & 2.21 & 0.33 & 0.38 & 31.96 & 54.42 & 14.04 & 14.63 \\
\hline Jarash & 1.69 & 5.06 & 2.24 & 2.92 & 0.52 & 1.87 & 0.27 & 0.37 & 30.54 & 37.03 & 11.90 & 12.71 \\
\hline Mafraq & 2.16 & 7.37 & 2.36 & 5.00 & 0.52 & 2.01 & 0.35 & 0.80 & 23.91 & 27.23 & 14.84 & 16.02 \\
\hline Balqa & 1.98 & 5.57 & 2.53 & 6.71 & 0.58 & 1.97 & 0.24 & 0.60 & 29.31 & 35.32 & 9.31 & 8.89 \\
\hline Zarqa & 2.83 & 6.08 & 2.87 & 13.72 & 0.45 & 2.53 & 0.19 & 1.24 & 15.84 & 41.57 & 6.80 & 9.03 \\
\hline Amman & 2.41 & 8.14 & 4.09 & 33.46 & 0.51 & 2.75 & 0.55 & 2.46 & 20.96 & 33.73 & 13.55 & 7.35 \\
\hline Madaba & 2.23 & 5.59 & 3.23 & 3.22 & 0.53 & 2.30 & 0.26 & 0.36 & 23.67 & 41.13 & 8.12 & 11.30 \\
\hline Karak & 1.36 & 4.42 & 3.41 & 5.97 & 0.41 & 1.99 & 0.30 & 0.73 & 29.79 & 45.04 & 8.83 & 12.22 \\
\hline Tafiela & 1.19 & 4.93 & 3.08 & 2.00 & 0.42 & 2.24 & 0.35 & 0.36 & 35.15 & 45.40 & 11.39 & 17.80 \\
\hline Ma'an & 2.04 & 5.69 & 3.42 & 2.56 & 0.52 & 2.21 & 0.57 & 0.38 & 25.41 & 38.94 & 16.71 & 14.98 \\
\hline Aqaba & 2.30 & 12.74 & 2.87 & 2.11 & 0.53 & 5.36 & 0.34 & 0.38 & 23.21 & 42.08 & 11.71 & 17.95 \\
\hline
\end{tabular}

Note. $\mathrm{DR}=$ divorce rate, $\mathrm{CR}=$ crime rate, $\mathrm{MR}=$ mortality rate, and $\mathrm{UP}=$ unemployment percentage.

Table 4. Descriptive Statistics in each Year across all Governorates

\begin{tabular}{|c|c|c|c|c|c|c|c|c|c|c|c|c|}
\hline \multirow[b]{2}{*}{ Year } & \multicolumn{4}{|c|}{ Mean } & \multicolumn{4}{|c|}{ Standard Deviation } & \multicolumn{4}{|c|}{ Coefficient of Variation } \\
\hline & DR & CR & MR & UP & DR & CR & MR & UP & DR & CR & MR & UP \\
\hline 2000 & 1.41 & 11.65 & 2.55 & 8.32 & 0.47 & 5.03 & 0.44 & 10.76 & 33.64 & 43.14 & 17.46 & 129.36 \\
\hline 2001 & 1.54 & 11.60 & 3.31 & 8.33 & 0.49 & 3.95 & 0.29 & 9.90 & 31.95 & 34.05 & 8.81 & 118.88 \\
\hline 2002 & 1.45 & 5.79 & 3.08 & 8.33 & 0.45 & 2.23 & 0.48 & 9.55 & 31.05 & 38.49 & 15.41 & 114.75 \\
\hline 2003 & 1.40 & 5.29 & 2.93 & 8.33 & 0.53 & 2.44 & 0.49 & 9.54 & 37.55 & 46.17 & 16.80 & 114.54 \\
\hline 2004 & 1.51 & 5.24 & 2.80 & 8.33 & 0.48 & 2.70 & 0.47 & 8.79 & 31.66 & 51.61 & 16.69 & 105.62 \\
\hline 2005 & 1.58 & 5.25 & 3.06 & 8.33 & 0.50 & 2.79 & 0.58 & 9.28 & 31.50 & 53.16 & 19.06 & 111.36 \\
\hline 2006 & 1.70 & 4.77 & 3.31 & 8.35 & 0.58 & 1.99 & 0.71 & 9.96 & 34.02 & 41.70 & 21.31 & 119.32 \\
\hline 2007 & 1.83 & 6.97 & 3.34 & 8.33 & 0.47 & 2.74 & 0.79 & 9.70 & 25.51 & 39.25 & 23.68 & 116.53 \\
\hline 2008 & 2.06 & 7.27 & 2.90 & 8.33 & 0.44 & 1.79 & 0.56 & 9.14 & 21.37 & 24.57 & 19.33 & 109.66 \\
\hline 2009 & 2.28 & 7.18 & 2.86 & 8.34 & 0.52 & 2.64 & 0.58 & 9.77 & 22.89 & 36.73 & 20.37 & 117.16 \\
\hline 2010 & 2.27 & 6.47 & 2.97 & 8.33 & 0.53 & 2.50 & 0.63 & 10.19 & 23.37 & 38.62 & 21.10 & 122.25 \\
\hline 2011 & 2.24 & 4.16 & 2.84 & 8.33 & 0.51 & 1.75 & 0.70 & 10.05 & 22.78 & 42.13 & 24.56 & 120.77 \\
\hline 2012 & 2.44 & 4.39 & 2.91 & 8.33 & 0.55 & 1.93 & 0.72 & 9.41 & 22.33 & 43.89 & 24.76 & 113.06 \\
\hline 2013 & 2.58 & 4.49 & 3.02 & 8.33 & 0.63 & 2.03 & 0.71 & 9.22 & 24.36 & 45.18 & 23.63 & 110.70 \\
\hline 2014 & 2.80 & 5.22 & 3.18 & 8.33 & 0.67 & 1.83 & 0.80 & 9.38 & 23.82 & 35.08 & 25.18 & 112.70 \\
\hline 2015 & 2.28 & 3.93 & 2.54 & 8.33 & 0.33 & 1.36 & 0.51 & 9.52 & 14.65 & 34.70 & 19.87 & 114.28 \\
\hline
\end{tabular}


percentage rise in the DR: 62\% from 2000 to 2015. The highest and lowest means in the DR were found in 2014 and 2003, respectively. The percentage change in the CR was dramatically unstable over the studied time period; however, the percentage decreased to $66 \%$ from 2000 to 2015. The highest and lowest means in the CR emerged in 2000 and 2015, respectively. The change in the UP was quite stable: 8.3\% over the time period under study.

As shown in Table 3, based on the coefficient of variation (CV), the highest variation in the DR, CR, MR, and UP over the period 2000-2015 emerged in Tafiela, Ajlun, Ma'an, and Aqaba and Tafiela, respectively. As shown in Table 4, based on the CV, we found the highest variation in the DR, CR, MR, and UP in the years of 2003, 2005,2015 , and 2000, respectively. We discerned that variation values, based on the CV, in the UP, over years, are dramatically higher than variation values across governorates.
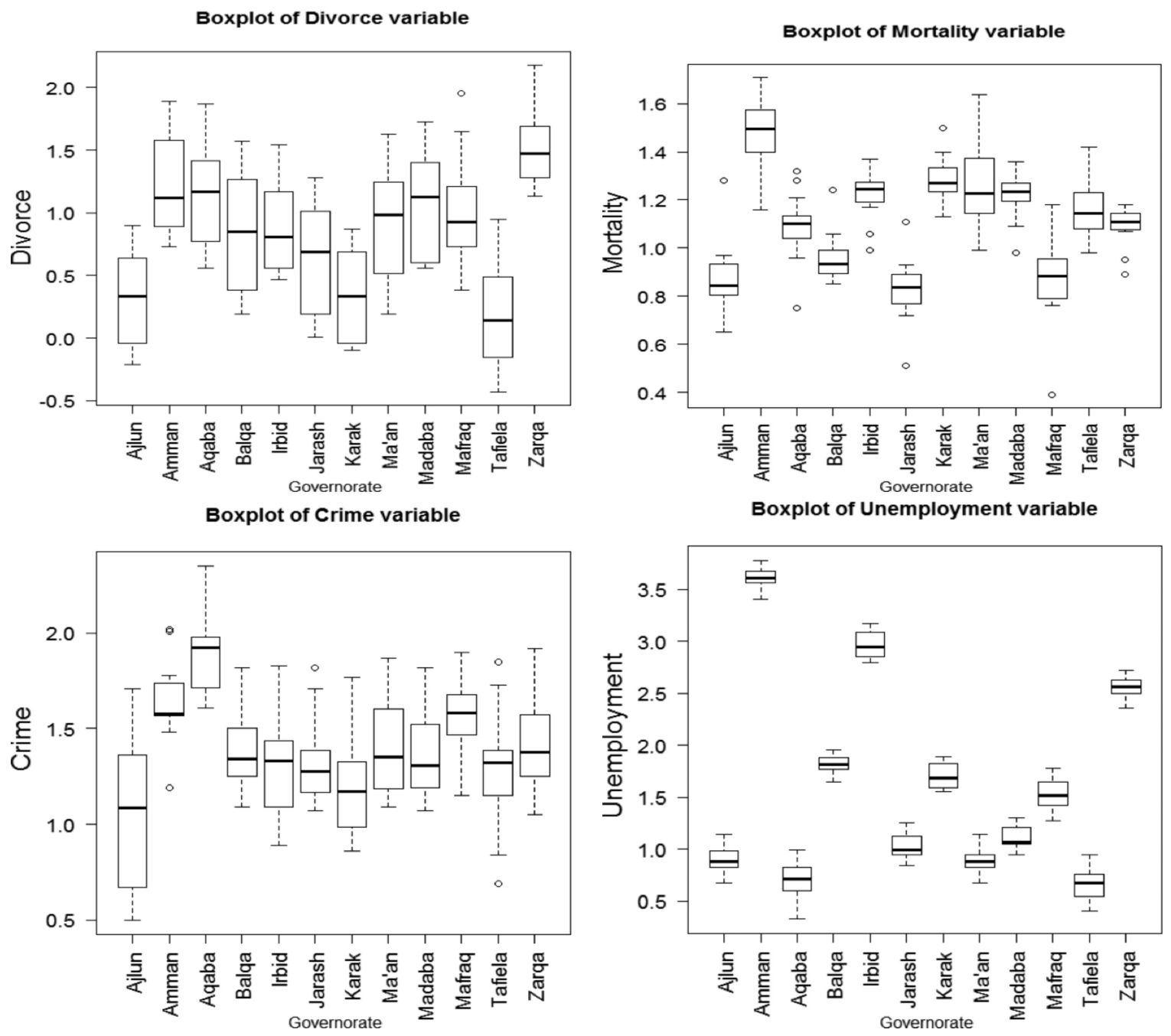

Figure 1. Boxplot of each dependent variable for the governorate factor.

Figures 1 and 2 show the boxplots for each DV, before transforming the data to the normal distribution, across the 12 governorates and over the 16 years respectively. We observed that all DVs differ between governorates and between years, except that unemployment did not differ between years. The differences in DVs between governorates are more pronounced than between years. As seen in Figure 2, differences between years in crime and divorce are more pronounced than in mortality. 


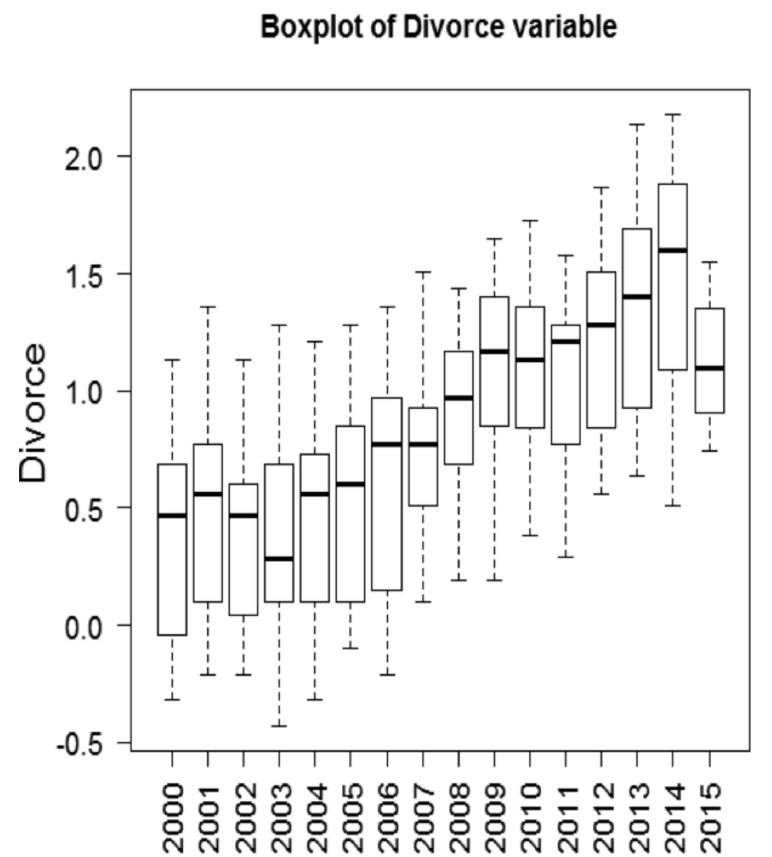

Boxplot of Mortality variable

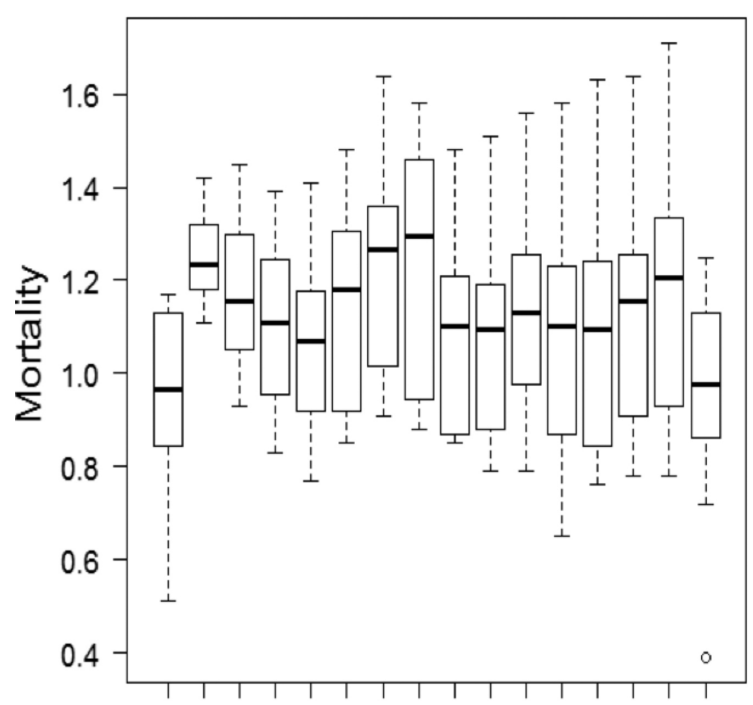

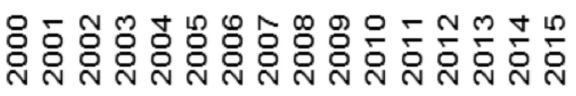

Year
Boxplot of Crime variable

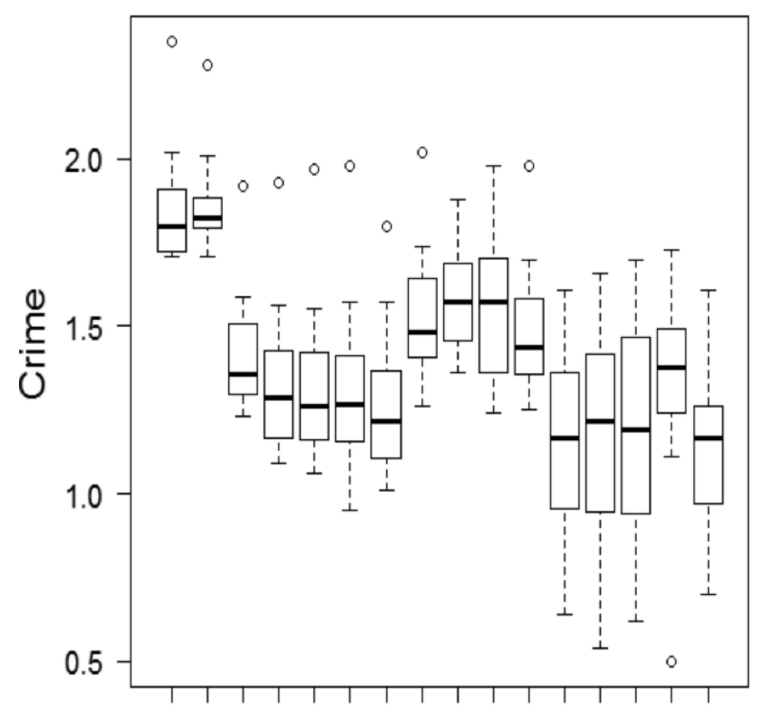

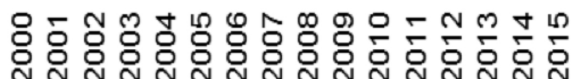

Year

Boxplot of Unemployment variable

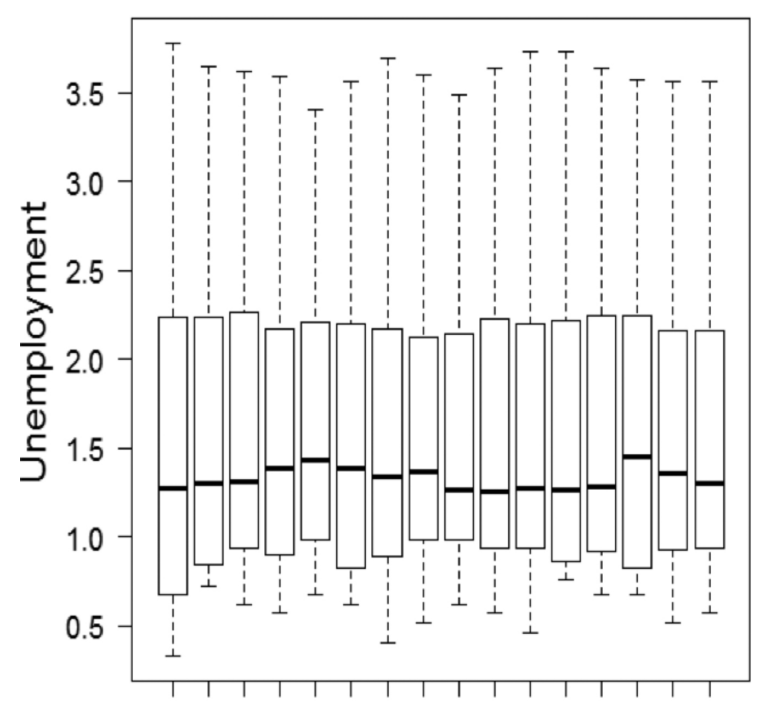

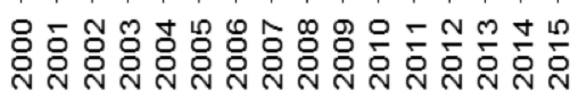

Year

Figure 2. Boxplot of each dependent variable for the year factor.

Table 5 shows significant main effects, with $p=.001$, of the governorate and year factors on all DVs based on four statistics: Pillai's trace, Wilks' lambda, Hotelling's trace, and Roy's largest root. The Wilks' lambda statistic can be interpreted as the proportion of variance in DVs unaccounted for by variation in the IVs. The small values 
of Wilks' lambda, shown in Table 5, indicate large differences between governorates and between years in all DVs. The values of Wilks' lambda for each governorate and year factor indicates that differences between the governorates and years accounts for the variance in DVs $(1-.01) \times 100=99 \%$. The Pillai's trace statistic is the proportion of variance in DVs accounted for by the variance in IVs. Hotelling's trace assesses the statistical significance of the difference of the mean of two or more variables between two groups of a variable. The larger the Hotelling's trace and the Pillai's trace, the more the given effect contributes to the model. The Roy's largest root gives an upper bound for the $F$-statistic. This criterion provides advantages in power and specificity of the test and is more appropriate when DVs strongly interrelate on a single dimension.

We estimated multivariate effect sizes using partial $\eta^{2}$. For example, as seen in Table $5, \eta^{2}$ for Wilks' Lambda was .89 for the governorate factor and .68 for the year factor, which implies that $89 \%$ and $68 \%$ of the variance in the canonically derived DVs accounted for by the governorate and year factors, respectively. The statistical power of the multivariate test appears in the last column of Table 5. Observed power to detect the effect rests on the assumption that the true difference in the population means is the difference implied by the sample means. Typically, we aim to calculate the power at the beginning of an experiment, based on anticipated or previous effect size in other similar studies. This technique is useful in making decisions about sample size. Therefore, observed power calculated here is not particularly useful because we studied the total population.

Because we found a significant multivariate main effect for each factor, we performed univariate $F$-tests. We looked at each DV, in turn, to investigate whether the two factors significantly impacted DVs separately. We conducted four tests because we used four DVs. We used an experiment-wise alpha rate of .05 divided by 4 to get an acceptable confidence level for each test. Therefore, we used $\alpha<.013$ as a significance level. Using this criterion and consistent with the multivariate results, univariate main effects of each factor on each DV were significant, as shown in Table 6, except the effect of year on unemployment was not significant.

We estimated univariate effect sizes using partial $\eta^{2}$. For example, as seen in Table 6, $\eta^{2}$ for divorce was 90 and .89 for governorate and year factors, respectively, which implies that the governorate and year factors accounted for

Table 5. Two-Factor Multivariate Tests of Variation on all Dependent Variables

\begin{tabular}{llrrrcc}
\hline Effect & \multicolumn{1}{c}{ Statistic } & Value & $F$-statistic & \multicolumn{2}{c}{$p$-value } & Partial $\eta^{2}$ Power of the test \\
\hline Governorate factor & Pillai's trace & 3.28 & 68.43 & $<0.001$ & 0.82 & 0.99 \\
& Wilks' lambda & 0.01 & 129.72 & $<0.001$ & 0.89 & 0.99 \\
& Hotelling's trace & 77.29 & 281.94 & $<0.001$ & 0.95 & 0.99 \\
Year factor & Roy's largest root & 63.86 & 957.83 & $<0.001$ & 0.99 & 0.99 \\
& Pillai's trace & 2.18 & 13.13 & $<0.001$ & 0.54 & 0.99 \\
& Wilks' lambda & 0.01 & 23.74 & $<0.001$ & 0.68 & 0.99 \\
& Hotelling's trace & 16.11 & 43.09 & $<0.001$ & 0.80 & 0.99 \\
& Roy's largest root & 12.52 & 137.71 & $<0.001$ & 0.93 & 0.99 \\
\hline
\end{tabular}

Note. a. Computed using $\alpha=.05$.

Table 6. Univariate Main Effect of Each Factor on Each Dependent Variable

\begin{tabular}{llrrcc}
\hline Effect & Dependent variable & $F$-statistic & $p$-value & Partial $\eta^{2}$ Power of the test \\
\hline Governorate factor & Divorce & 135.92 & $<0.001$ & 0.90 & 0.99 \\
& Crime & 54.46 & $<0.001$ & 0.78 & 0.99 \\
& Mortality & 71.04 & $<0.001$ & 0.83 & 0.99 \\
Year factor & Unemployment & 874.47 & $<0.001$ & 0.98 & 0.99 \\
& Divorce & 89.02 & $<0.001$ & 0.89 & 0.99 \\
& Crime & 44.76 & $<0.001$ & 0.80 & 0.99 \\
& Mortality & 10.59 & $<0.001$ & 0.49 & 0.99 \\
& Unemployment & 0.83 & 0.642 & 0.07 & 0.53 \\
\hline
\end{tabular}

Note. a. Computed using $\alpha=.05$. 
$90 \%$ and $89 \%$ of the variance in divorce, respectively. Governorate and year factors with almost the same amount of $\eta^{2}$ explained the variance in divorce and crime. The governorate factor of $83 \%$ explained the variance in mortality; much higher than its explanation by the year factor, with $49 \%$. In addition, the governorate factor accounted for $98 \%$ of the variance in unemployment.

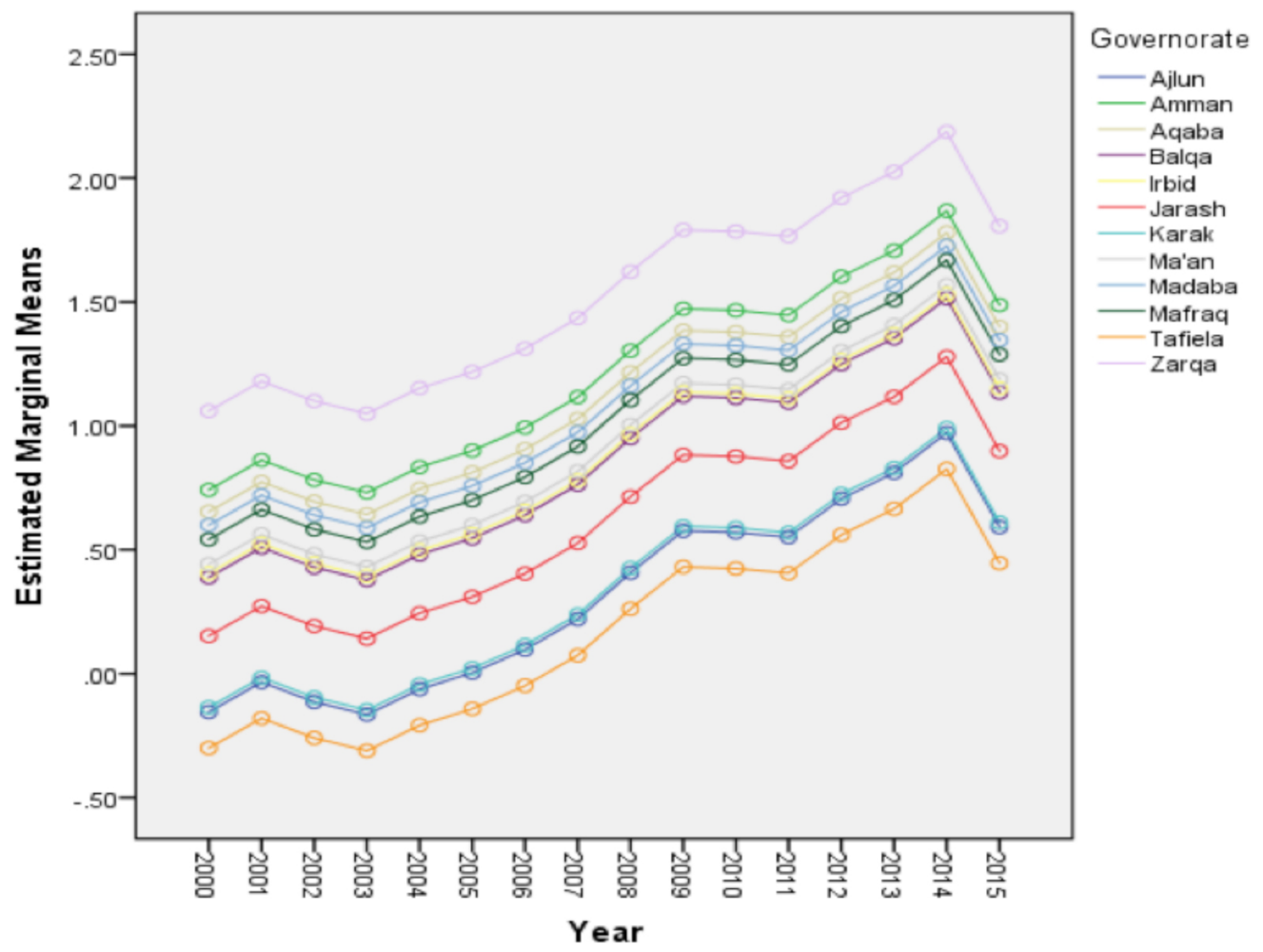

Figure 3. Variation in divorce between governorates over the period 2000-2015.

Tables 7 and 8 show univariate tests for the marginal and grand means of each DV, based on a 95\% confidence interval in each governorate and each year. We tested the null hypothesis stating that the marginal mean (in each governorate and each year) and the grand mean of each DV equals zero. Based on the results, we rejected the null hypothesis, meaning the marginal and grand means of each DV in each governorate and each year were significant.

We plotted marginal means of each governorate along the horizontal time factor for each DV. As shown in Figure 3, an increased trend emerged in divorce over time with high variation among governorates. Figure 4 shows a decreasing trend in crime over time, high variation between governorates, and variation between some periods of time. Figure 5 shows no trend in mortality over time but high variation between governorates. Figure 6 shows high stability in unemployment over time and high variation between governorates.

We found significant univariate main effect of governorate factor for each DV. The question remained, what is the mean difference between governorates for each DV, considered two at a time. Therefore, we tested the null hypothesis for each DV $\left(\mu_{i}-\mu_{j}=0\right.$, where $i, j=1,2, \ldots 12$ governorate and $\left.i \neq j\right)$. Test results of pairwise comparisons of the mean difference between the $i$ th and $j$ th governorate for each DV were significant, with most $p=.001$, some $p=.01$, and others $p=.05$; however, test results, shown in Table 8, were not significant. From Table 8, we discerned that no differences emerged between some governorates in several DVs. For example, no mean differences arose in divorce and crime between Balqa and both Irbid and Ma'an. Furthermore, no mean difference in crime emerged between many governorates. In addition, most mean differences between many governorates in unemployment was significant, supported by a visual inspection, shown in Figure 6. Table 9 shows insignificant test results of pairwise comparisons of the mean difference between the $i$ th and $j$ th governorates for each DV. 


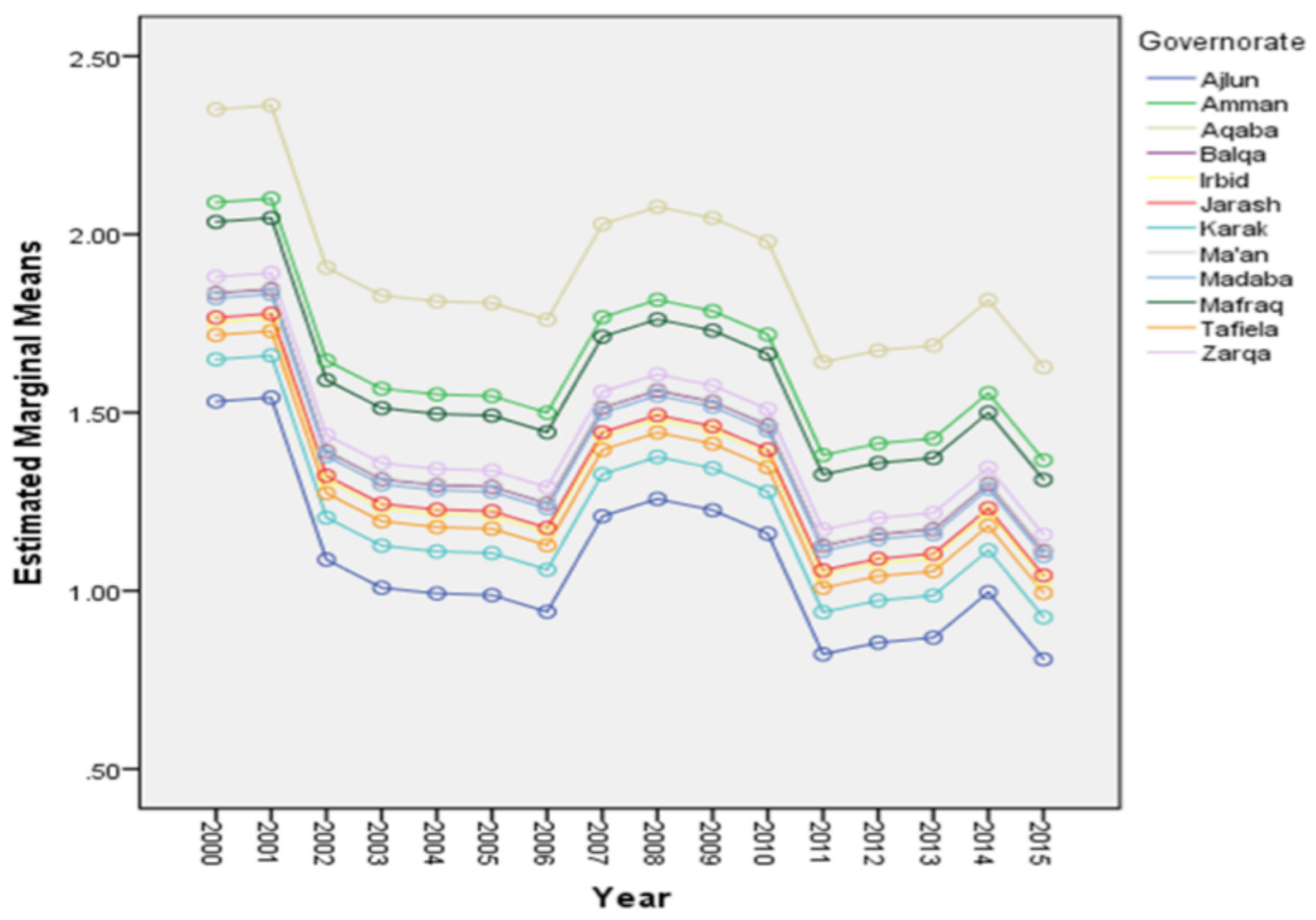

Figure 4. Variation in crime between governorates over the period 2000-2015.

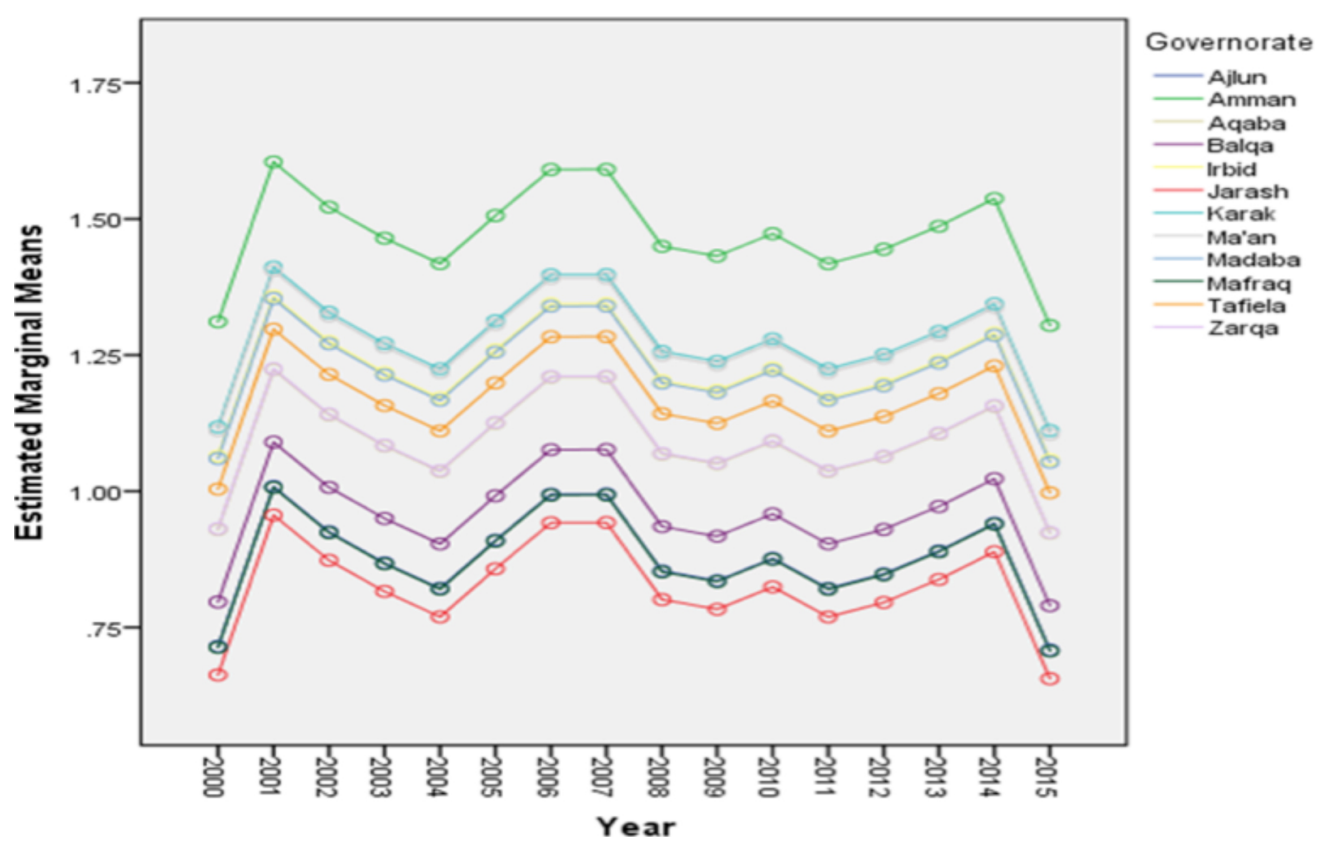

Figure 5. Variation in mortality between governorates over the period 2000-2015. 


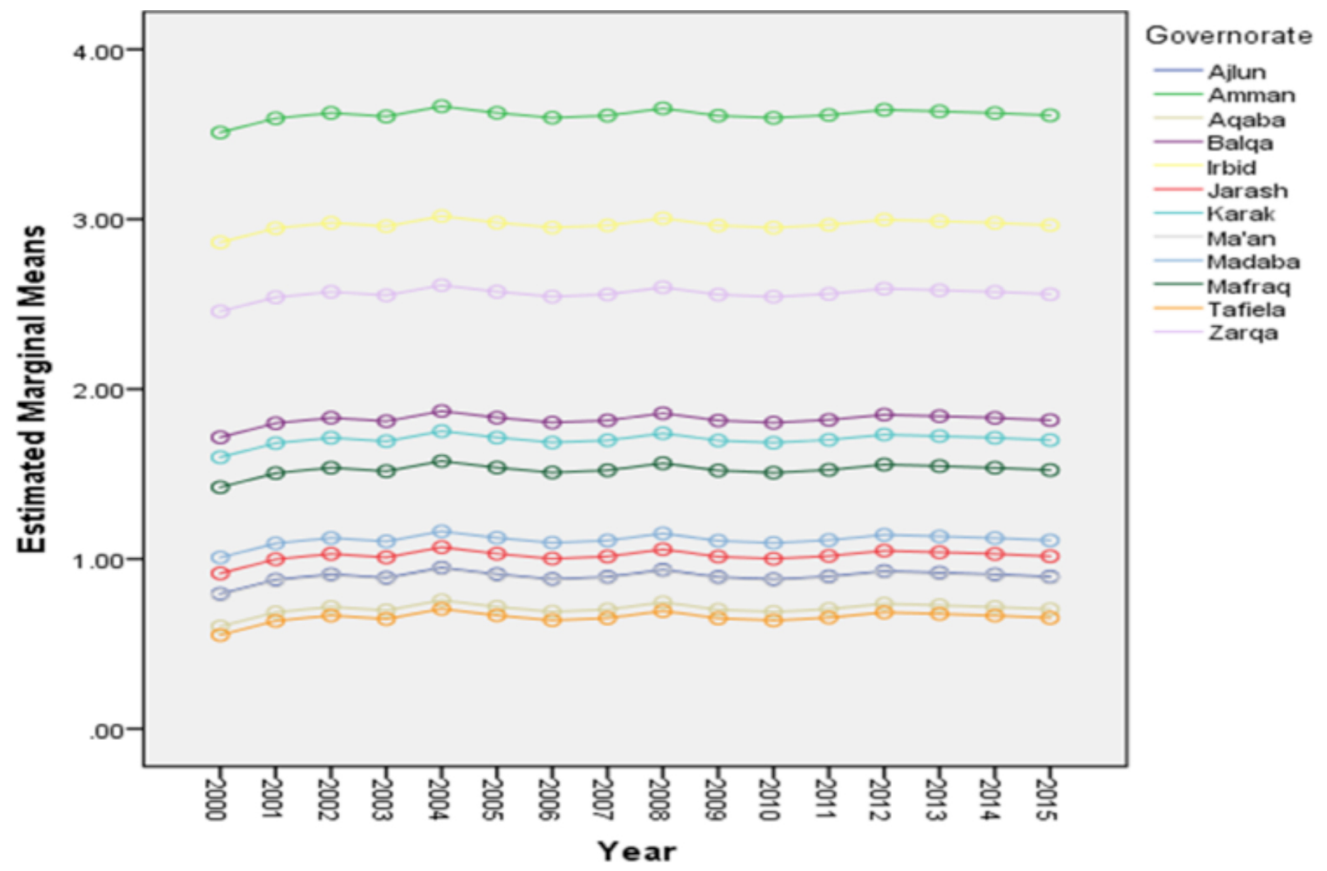

Figure 6. Variation in unemployment between governorates over the period 2000-2015.

\section{Discussion}

Regarding the primary hypotheses that there are no main governorate and year effects on the DVs, collectively and separately, multivariate tests were significant. This result means that DVs were affected collectively by IVs. The next question in the analysis was to determine whether the governorate and year factors affected DVs separately. We found that both factors had a significant effect on each DV to different extents, except that unemployment was not affected by the year factor. In addition, no interaction effect between governorates and years on any DV was significant. This outcome means that mean values of any DV did not change when varying both levels of the

Table 7. Margial and Grand Means of Each Dependent Variable in Each Governorate

\begin{tabular}{lcccccccc}
\hline & \multicolumn{7}{c}{ Mean (95\% confidence interval) } \\
\cline { 2 - 9 } Governorate & \multicolumn{2}{c}{ Divorce } & \multicolumn{2}{c}{ Crime } & \multicolumn{2}{c}{ Mortality } & \multicolumn{2}{c}{ Unemployment } \\
\hline Ajlun & 0.31 & $(0.42,0.38)$ & 1.08 & $(1.02,1.14)$ & 0.88 & $(0.83,0.92)$ & 0.90 & $(0.83,0.96)$ \\
Amman & 1.21 & $(1.14,1.28)$ & 1.64 & $(1.58,1.70)$ & 1.47 & $(1.43,1.52)$ & 3.61 & $(3.55,3.68)$ \\
Aqaba & 1.12 & $(1.05,1.19)$ & 1.90 & $(1.84,1.96)$ & 1.09 & $(1.04,1.14)$ & 0.71 & $(0.64,0.77)$ \\
Balqa & 0.85 & $(0.79,0.92)$ & 1.39 & $(1.33,1.44)$ & 0.96 & $(0.91,1.00)$ & 1.82 & $(1.76,1.88)$ \\
Irbid & 0.87 & $(0.80,0.94)$ & 1.30 & $(1.25,1.36)$ & 1.23 & $(1.18,1.27)$ & 2.97 & $(2.90,3.03)$ \\
Jarash & 0.62 & $(0.55,0.69)$ & 1.32 & $(1.26,1.37)$ & 0.82 & $(0.78,0.87)$ & 1.02 & $(0.95,1.08)$ \\
Karak & 0.33 & $(0.26,0.40)$ & 1.20 & $(1.14,1.26)$ & 1.28 & $(1.23,1.33)$ & 1.70 & $(1.64,1.77)$ \\
Ma'an & 0.91 & $(0.84,0.98)$ & 1.39 & $(1.33,1.45)$ & 1.27 & $(1.23,1.32)$ & 0.89 & $(0.83,0.96)$ \\
Madaba & 1.07 & $(1.00,1.13)$ & 1.37 & $(1.31,1.43)$ & 1.22 & $(1.18,1.27)$ & 1.11 & $(1.05,1.18)$ \\
Mafraq & 1.01 & $(0.94,1.08)$ & 1.59 & $(1.53,1.64)$ & 0.87 & $(0.83,0.92)$ & 1.53 & $(1.46,1.59)$ \\
Tafiela & 0.17 & $(0.10,0.23)$ & 1.27 & $(1.21,1.33)$ & 1.17 & $(1.12,1.21)$ & 0.66 & $(0.59,0.72)$ \\
Zarqa & 1.53 & $(1.46,1.59)$ & 1.43 & $(1.37,1.49)$ & 1.09 & $(1.05,1.14)$ & 2.56 & $(2.50,2.63)$ \\
Grand mean & 0.83 & $(0.81,0.85)$ & 1.41 & $(1.39,1.42)$ & 1.11 & $(1.1,1.13)$ & 1.62 & $(1.60,1.64)$ \\
\hline
\end{tabular}


governorate and year factors. However, even if we found significant interaction effect, it would be a big challenge to find a satisfied interpretation.

Regarding the secondary hypotheses that the grand and marginal means of each DV equal zero, all tests were significant. Regarding the secondary hypothesis that the mean difference between two governorates in each DV equals zero, most pairwise comparisons were significant. However, most significant pairwise comparisons were found in unemployment, followed by divorce, mortality, and crime. We investigated the results of pairwise comparisons between years in all DVs but do not report the results; they are available upon request. Briefly, in divorce and crime, we found a significant mean difference between most years. For mortality, we found no significant mean difference between most years; exceptions were between the years of 2000, 2001, 2006, 2007, and 2015, and others. For unemployment, we found no significant mean difference between most years. These results are supported by line charts (see Figures 3-6).

Here, we explain similarities and differences between current study results and the work of others. The effect of unemployment on crime has been the source of a long-standing disagreement in criminology because many studies found conflicting results, due to the omission of historical context, by treating any period of years as a sample of any other period of years [3]. Although, the goal of the current study was not to find the relationship between unemployment and crime, the variance in unemployment and crime was significant due to the governorate factor. The spatial study by Khamis [10] in Jordan confirmed the finding of significant local clusters in unemployment in the central and western parts of the country. In the United States, Bloom, Canning, and Sevilla [2], using regression analysis, stated that if an increase in the working-age population is not matched by increased job opportunities, unemployment could rise, leading to higher crime rates. Therefore, a high possibility exists that the working-age population in Jordan is not matched by increased job opportunities. Findings from the current study on variance in DVs between governorates agree with findings from the Maslauskaite, Jasilioniene, Jasilionis, Stankuniene, and Shkolnikov [16] study that individual socioeconomic recourse has substantial differentiating effects on divorce risk in Lithuania, where the direction and size of these effects vary notably by sex and place of residence. In addition, Maslauskaite et al. found that unemployment aligns with higher divorce probabilities using Poisson regression models; whereas in the present study we found some governorates vary in divorce and unemployment. Unemployment and financial problems were found the main causes of divorce in some cases, aligned with Ghoreishi, Shirmohammadi, and Barjvand [6] in Saghez City, Kurdistan Province, Iran, where they used social constructivism as a methodological approach. In the current study, the variance in unemployment

Table 8. Marginal Means of Each Dependent Variable with 95\% Confidence Interval in Each Year

\begin{tabular}{lllllllll}
\hline & \multicolumn{7}{c}{ Mean (95\% confidence interval) } \\
\cline { 2 - 9 } Year & \multicolumn{2}{c}{ Divorce } & \multicolumn{2}{c}{ Crime } & \multicolumn{2}{c}{ Mortality } & \multicolumn{2}{c}{ Unemployment } \\
\hline 2000 & 0.37 & $(0.29,0.45)$ & 1.86 & $(1.79,1.92)$ & 0.95 & $(0.90,1.01)$ & 1.52 & $(1.45,1.59)$ \\
2001 & 0.49 & $(0.41,0.57)$ & 1.87 & $(1.80,1.93)$ & 1.25 & $(1.19,1.30)$ & 1.60 & $(1.53,1.68)$ \\
2002 & 0.41 & $(0.33,0.49)$ & 1.41 & $(1.35,1.48)$ & 1.16 & $(1.11,1.22)$ & 1.63 & $(1.56,1.71)$ \\
2003 & 0.36 & $(0.28,0.44)$ & 1.33 & $(1.27,1.40)$ & 1.11 & $(1.05,1.16)$ & 1.61 & $(1.54,1.69)$ \\
2004 & 0.46 & $(0.38,0.54)$ & 1.32 & $(1.25,1.38)$ & 1.06 & $(1.01,1.11)$ & 1.67 & $(1.60,1.75)$ \\
2005 & 0.52 & $(0.45,0.60)$ & 1.31 & $(1.25,1.38)$ & 1.15 & $(1.09,1.20)$ & 1.64 & $(1.56,1.71)$ \\
2006 & 0.62 & $(0.54,0.70)$ & 1.27 & $(1.20,1.33)$ & 1.23 & $(1.18,1.29)$ & 1.61 & $(1.53,1.68)$ \\
2007 & 0.74 & $(0.66,0.82)$ & 1.53 & $(1.47,1.60)$ & 1.23 & $(1.18,1.29)$ & 1.62 & $(1.55,1.69)$ \\
2008 & 0.93 & $(0.85,1.01)$ & 1.58 & $(1.52,1.65)$ & 1.09 & $(1.04,1.14)$ & 1.66 & $(1.59,1.74)$ \\
2009 & 1.10 & $(1.02,1.18)$ & 1.55 & $(1.48,1.62)$ & 1.07 & $(1.02,1.13)$ & 1.62 & $(1.54,1.69)$ \\
2010 & 1.09 & $(1.01,1.17)$ & 1.49 & $(1.42,1.55)$ & 1.11 & $(1.06,1.17)$ & 1.61 & $(1.53,1.68)$ \\
2011 & 1.07 & $(0.99,1.15)$ & 1.15 & $(1.08,1.21)$ & 1.06 & $(1.01,1.11)$ & 1.62 & $(1.55,1.70)$ \\
2012 & 1.23 & $(1.15,1.31)$ & 1.18 & $(1.11,1.25)$ & 1.09 & $(1.03,1.14)$ & 1.65 & $(1.58,1.73)$ \\
2013 & 1.33 & $(1.25,1.41)$ & 1.19 & $(1.13,1.26)$ & 1.23 & $(1.07,1.18)$ & 1.64 & $(1.57,1.72)$ \\
2014 & 1.49 & $(1.41,1.57)$ & 1.32 & $(1.25,1.39)$ & 1.18 & $(1.12,1.23)$ & 1.63 & $(1.56,1.71)$ \\
2015 & 1.11 & $(1.03,1.19)$ & 1.13 & $(1.07,1.20)$ & 0.95 & $(0.89,1.00)$ & 1.62 & $(1.55,1.69)$ \\
\hline & & & & & & & &
\end{tabular}


and divorce arose in some governorates. Jalovaara [8] found that unemployment led to increased divorce risk in Finland using the Poisson regression model. However, we agree with a recommendation of Lin, Zhang, Chen, and Ling [15] study stating that social activities to facilitate employment and creating generalized trust within social environments should be promoted. In addition, French young people having a non-working occupational status or a non-permanent working status were more exposed to poor self-perceived health, poor mental health, addictions and violence [1], where they used the stepwise forward logistic regression.

Which specific governorate was found to be significantly different from others (i.e., rejecting the null hypothesis of the two equal governorates means in such a DV)? For divorce, these governorates were Jarash, Tafiela, and Zarqa. For crime, these governorates were Ajlun and Aqaba. For mortality, these governorates were Amman and Balqa. For unemployment, these governorates were Amman, Balqa, Irbid, Jarash, Karak, Madaba, Mafraq, and Zarqa. Thus, many governorates were different in their unemployment mean compared with other DV means. However, Jarash and Zarqa were different from all governorates in divorce and unemployment. In addition, Amman and Balqa

Table 9. Insignificant Test Results of Pairwise Comparisons of Mean Differences in Governorates for Each Dependent Variable in the $i$ th and $j$ th Governorates

\begin{tabular}{|c|c|c|c|c|c|}
\hline \multirow[b]{2}{*}{$i$ th governorate } & \multirow[b]{2}{*}{$j$ th governorate } & \multicolumn{4}{|c|}{$p$-value } \\
\hline & & Divorce & Crime & Mortality & Unemployment \\
\hline Ajlun & Karak & 0.708 & & & \\
\hline Amman & Aqaba & 0.076 & & & \\
\hline Aqaba & Madaba & 0.275 & & & \\
\hline \multirow[t]{2}{*}{ Balqa } & Irbid & 0.732 & 0.053 & & \\
\hline & Ma'an & 0.281 & 0.939 & & \\
\hline Irbid & Ma'an & 0.462 & & 0.158 & \\
\hline Madaba & Mafraq & 0.242 & & & \\
\hline Amman & Mafraq & & 0.191 & & \\
\hline \multirow[t]{3}{*}{ Balqa } & Jarash & & 0.101 & & \\
\hline & Madaba & & 0.736 & & \\
\hline & Zarqa & & 0.277 & & \\
\hline \multirow[t]{3}{*}{ Irbid } & Jarash & & 0.761 & & \\
\hline & Madaba & & 0.108 & 0.899 & \\
\hline & Tafiela & & 0.383 & 0.071 & \\
\hline \multirow[t]{3}{*}{ Jarash } & Ma'an & & 0.086 & & \\
\hline & Madaba & & 0.192 & & \\
\hline & Tafiela & & 0.240 & & \\
\hline Karak & Tafiela & & 0.103 & & \\
\hline \multirow[t]{2}{*}{ Ma'an } & Madaba & & 0.680 & 0.124 & \\
\hline & Zarqa & & 0.312 & & \\
\hline Madaba & Zarqa & & 0.155 & & \\
\hline \multirow[t]{2}{*}{ Ajlun } & Jarash & & & 0.114 & \\
\hline & Mafraq & & & 0.948 & \\
\hline Aqaba & Zarqa & & & 0.963 & \\
\hline Irbid & Karak & & & 0.107 & \\
\hline Jarash & Mafraq & & & 0.130 & \\
\hline \multirow[t]{2}{*}{ Karak } & Ma'an & & & 0.842 & \\
\hline & Madaba & & & 0.083 & \\
\hline Madaba & Tafiela & & & 0.093 & \\
\hline Ajlun & Ma'an & & & & 0.877 \\
\hline Aqaba & Tafiela & & & & 0.270 \\
\hline
\end{tabular}


were different from all governorates in mortality and unemployment. Hence, based on these findings, policymakers can decide to which governorates priority should be given to minimize variation in DVs from the others.

The current study findings are important for the following reasons: First, solving socioeconomic, health, and insecurity problems in any country can build productive and creative communities. People in these communities interact effectively, share experiences, develop valued relationships, and work toward common goals. Without communities, people would live isolated, with minimal or no contact outside of their immediate circle. Getting to know new people is essential to the enrichment of a person's life. Second, the current study contributes to the fields of social, economic, health, and security in the form of theoretical and practical implications. Third, by providing sufficient information about reasons for variation in DVs between governorates and years, policymakers can plan for a more efficient distribution of the country's resources. Fourth, by determining which governorates are unequal in their socioeconomic and health characteristics, awareness and guidance programs should be undertaken in these governorates. Fifth, based on examining all technique assumptions and ensuring appropriate statistical treatment in case of their violation, study findings are valid and replicable. Sixth, policymakers may use these findings to identify and justify priorities in protection and health promotion. Therefore, the statistical technique used in the present study is applicable to investigating many variables in many related fields.

Some issues remained unresolved or did not consider in the present study. For example, we did not determine which DV was affected by which other DV? Does any DV in a governorate correlates with itself in other neighboring governorates? For the first question, we could use a multivariate analysis of covariance (MANCOVA) technique. In using MANCOVA, one can examine the effect of factors (independent grouping variables), multiple covariates such as the education, income, and similar DVs, on other DVs. Covariates can reduce error and the analysis could eliminate covariates' effect on the relationship between the independent-grouping variables and the DVs. For the second question, we can use spatial-autocorrelation measures that consider the spatial neighboring weight. That is, we could use spatial statistics to find spatial correlations among the same DVs. In addition, we did not consider the variation in DVs by gender.

\section{Conclusions and Recommendations}

Findings show that multiple variables are important in interpreting variations between governorates. The conclusions can be explained in at least six aspects. First, we found that the governorate and year factors significantly impact the four DVs, based on a multivariate test. However, the effect of the governorate factor on DVs, collectively and separately, was more than the effect of the year factor. Second, based on univariate tests, we found that each DV was highly significantly different between governorates and between years, except unemployment was not significantly different between years. Third, divorce was affected by governorate and year factors more than crime and mortality variables. Fourth, the grand and marginal means of each DV were significant in each governorate and each year. Fifth, based on pairwise-comparison tests, the mean difference of each DV between two governorates was significant, in general, with varying significance levels. Sixth, based on visual inspection, the patterns of divorce and crime showed increasing and decreasing trends over time, respectively. In addition, patterns of mortality and unemployment show high fluctuation and stability trends over time, respectively.

The increase in government spending on health, household access to health insurance, social and security awareness, and the level of income, and reducing taxes can lead to reducing the variance between governorates in studied variables. Further controlling crime, divorce, and unemployment may have important positive effects on population health. A change is required in government policy in the distribution of financial and human resources to governorates. Therefore, a financial subsidy, social awareness, and health services should be directed toward governorates that suffer higher rates of socioeconomic, health, and insecurity problems compared with other governorates; the government should devote a high proportion of resources to these governorates. In addition, the government can design management strategies to mitigate the risk of increasing the variance in socioeconomic and security variables between and within governorates. Study results can be used to help local policymakers make appropriate health-policy decisions. Further research is required regarding the study of other socioeconomic variables such as education and income. 


\section{REFERENCES}

1. M. Blanquet, E. Labbe-Lobertreau, C. Sass, D. Berger, and L. Gerbaud, Occupational status as a determinant of mental health inequities in French young people: Is fairness needed? Results of a cross-sectional multicentre observational survey, International Journal for Equity in Health, vol. 16, no. 142, pp. 1-10, 2017.

2. D. E. Bloom, D. Canning, and J. Sevilla, Economic Growth and the Demographic Transition, Boston, MA, National Bureau of Economic Research, http: //www. nber.org/papers/w8685, 2001.

3. S. M. Carlson, and R. J. Michalowski, Crime, unemployment, and social structures of accumulation: An inquiry into historical contingency, Justice Quarterly, vol. 14, no. 2, pp. 209-241, 1997.

4. M. De Goede, and E. Spruijt, Effects of parental divorce and youth unemployment on adolescent health, Patient Education and Counseling, vol. 29, no. 3, pp. 269-276, 1996.

5. D. Diener, R. Inglehart, and L. Tay, Theory and validity of life satisfaction scales, Social Indicators Research, vol. 112, no. 3, pp. 497-527, 2013

6. F. Ghoreishi, D. Shirmohammadi, and A. Barjvand, Understanding causes of divorce from the viewpoints of the divorced and divorcing couples (the case of Saghez City), Security and Social Order Strategic Studies Journal, vol. 3, no. 1, pp. 19-30, 2014.

7. J. F. Hair, R. E. Anderson, R. E. Anderson, and W. Black, Multivariate Data Analysis, 5th ed., Prentice Hall, Upper Saddle River, NJ, 1998.

8. M. Jalovaara, Socioeconomic differentials in divorce risk by duration of marriage, Demographic Research, vol. 7, pp. 537-564, 2002.

9. Y. M. Kantar, and S. G. Aktas, Spatial correlation analysis of unemployment rates in Turkey, Journal of Eastern Europe Research in Business and Economics, vol. 2016, pp. 1-9, 2016.

10. F. G. Khamis, Spatial dimensions of the unemployment rate in Jordan 2008, Austrian Journal of Statistics, vol. 40, no. 3, pp. 177190, 2011.

11. F. G. Khamis, G. A. El-Refae, and A.-R. F. Fares, Multivariate spatial association between mortality, unemployment, divorce, and crime in Jordan-2011, Journal of Statistical and Econometric Methods, vol. 3, no. 1, pp. 49-74, 2014.

12. M. Kriegbaum, U. Christensen, R. Lund, and M. Osler, Job losses and accumulated number of broken partnerships increase risk of premature mortality in Danish men born in 1953, Journal of Occupational And Environmental Medicine, vol. 51, no. 6, pp. 708-713, 2009.

13. D. Lester, The Impact of Unemployment on Marriage and Divorce, Journal of Divorce \& Remarriage, vol. 25, no. 3-4, pp. 151-153, 1996.

14. D. Lester, and B. Yang, The relationship between divorce, unemployment and female participation in the labour force and suicide rates in Australia and America, The Australian And New Zealand Journal of Psychiatry, vol. 25, no. 4, pp. 519-523, 1991.

15. Y. Lin, Q. Zhang, W. Chen, and L. Ling, The social income inequality, social integration and health status of internal migrants in China, International Journal for Equity in Health, vol. 16, pp. 139-150, 2017.

16. A. Maslauskaite, A. Jasilioniene, D. Jasilionis, V. Stankuniene, and V. M. Shkolnikov, Socio-economic determinants of divorce in Lithuania: Evidence from register-based census-linked data, Demographic Research, vol. 33, no. 30, pp. 871-908, 2015.

17. M. Umeda, N. Kawakami, and E. Miller, Effect of socioeconomic conditions on health care utilization in marital violence: a crosssectional investigation from the Japanese Study on Stratification, Health, Income, and Neighborhood, International Journal for Equity in Health, vol. 16, no. 41, pp. 1-9, 2017.

18. M. S. Wong, H. C. Ho, L. Yang, W. Shi, J. Yang, and T.-C. Chan, Spatial variability of excess mortality during prolonged dust events in a high density city: a time stratified spatial regression approach, International Journal of Health Geographics, vol. 16, no. 26, pp. 1-14, 2017. 